\title{
Ultrasound imaging in urogynecology - state of the art 2016
}

\author{
Michał Bogusiewicz \\ $2^{\text {nd }}$ Department of Gynecology, Medical University of Lublin, Poland
}

\begin{abstract}
The role of ultrasound imaging in urogynecology is not clearly defined. Despite significant developments in visualization techniques and interpretation of images, pelvic ultrasound is still more a tool for research than for clinical practice. Structures of the lower genitourinary tract and pelvic floor can be visualized from different approaches: transperineal, introital, transvaginal, abdominal or endoanal. According to contemporary guidelines and recommendations, the role of ultrasound in urogynecology is limited to the measurement of postvoid residue. However, in many instances, including planning and audit of surgical procedures, management of recurrences or complications, ultrasound may be proposed as the initial examination of choice. Ultrasound may be used for assessment of bladder neck mobility before anti-incontinence procedures. On rare occasions it is helpful in recognition of pathologies mimicking vaginal prolapse such as vaginal cyst, urethral diverticula or rectal intussusception. In patients subjected to suburethral slings, causes of surgery failure or postsurgical voiding dysfunctions can be revealed by imaging. Many reports link the location of a tape close to the bladder neck to unfavorable outcomes of sling surgery. Some postoperative complications, such as urinary retention, mesh malposition, hematoma, or urinary tract injury, can be diagnosed by ultrasound. On the other hand, the clinical value of some applications of ultrasound in urogynecology, for example measurement of the bladder wall thickness as a marker of detrusor overactivity, has not been proved.
\end{abstract}

Key words: ultrasound imaging, urinary incontinence, pelvic organ prolapse.

\section{Introduction}

The introduction of ultrasound imaging into the evaluation of urogynecological patients dates back to the early 1980s. Despite significant developments in visualization techniques and interpretation of images, pelvic ultrasound is still not widely accepted as a standard tool in clinical practice. Disagreement between working groups, lack of reproducibility of published results, and poor standardization are the main reasons why in all the guidelines and recommendations the role of ultrasound examination is limited to the measurement of post-void residue (PVR). However, the spectrum of therapeutic modalities in urogynecology, including use of synthetic implants, has widened considerably in recent years. Correspondingly, new applications of pelvic ultrasound such as surgery audit, management of recurrences or complications have been proposed. The aim of this paper is to present contemporary data on clinical use of ultrasound imaging in urogynecology.

\section{Ultrasound imaging modalities in urogynecology}

Structures of the lower genitourinary tract and pelvic floor can be visualized from different approaches. Each modality has its advantages and drawbacks regarding image quality, clinical utility or the availability of advanced equipment [1].

\section{Transperineal ulfrosound}

Transperineal ultrasound (TUS) is carried out with a 3.5 to $6 \mathrm{MHz}$ curved array transducer placed on the perineum in the midsagittal line. Examination is usually performed in the dorsal lithotomy position with the hips flexed and abducted. The resulting image contains the symphysis pubis, urethra, bladder, vagina, rectum and anal canal (Fig. 1). Other findings include the uterus, the cul-de-sac with bowels and fluid as well as synthetic implants or pelvic pathologies. The symphysis pubis (SP) is used as a stable landmark serving as a reference for evaluation of the bladder neck position and mobility. Full rectum, gas in rectum, pelvic organ prolapse, vaginal scar tissue or synthetic implants may impair visibility [1-4]. There is no agreement on image orientation. Some prefer cranial structures at the top, others at the bottom of the screen [2-4].

\section{D/4D transperineal ulfrasound}

Examination is performed with transducers developed for obstetric imaging. 


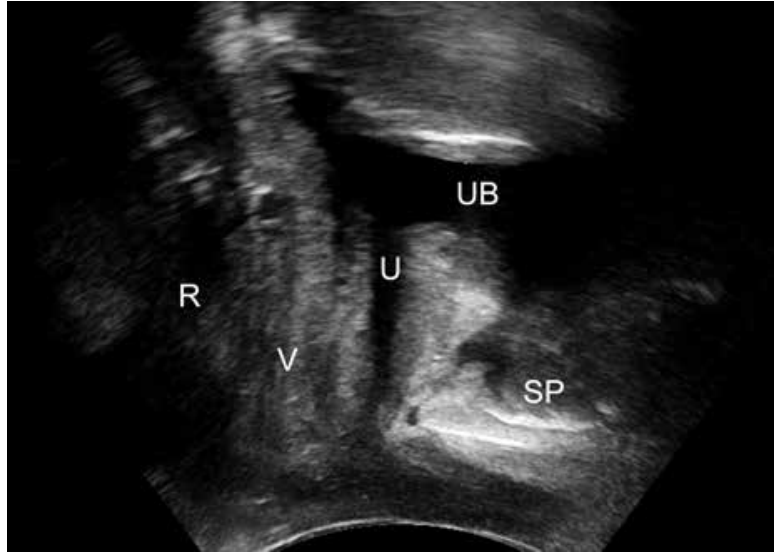

$U$ - urethra, UB - urinary bladder, $V$ - vagina, $S P$ - symphysis pubis, $R$ - rectum

Fig. 1. Transperineal examination in the midsagittal plane

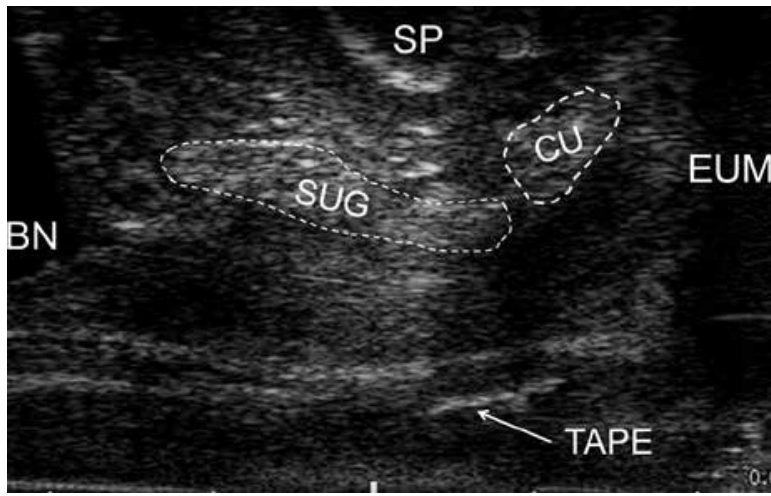

Fig. 2. Transvaginal examination with the biplane electronic probe (linear perpendicular arrays used) in a patient after suburethral sling procedure. Some subtle structures of the urethral complex can be distinguished

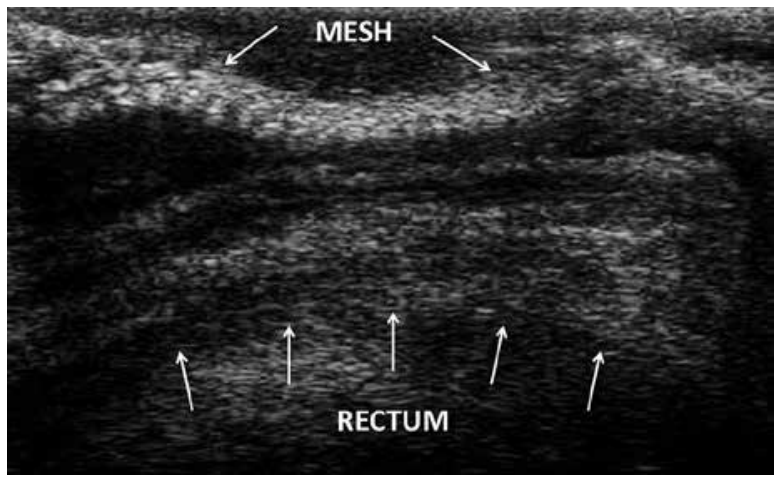

Fig. 3. Patient after posterior vaginal mesh. Posterior compartment examined with transvaginal biplane electronic probe (linear perpendicular arrays used)

Since the technique enables one to obtain tomographic or multislice scans, the whole puborectalis muscle and its attachments to the pubic rami can be visualized [1, 3, 5]. Dietz et al. using 3D/4D TUS identified specific labor-related damage to the puborectalis muscle termed avulsion. It is the result of the detachment of the muscle from its insertion on the inferior pubic ramus and the pelvic side- wall as a consequence of overstretching of the levator during the second stage of labor and may be detected in up to $36 \%$ of women following their first vaginal delivery. Damage to the levator muscle leads to enlargement of the levator hiatus, which on 4D TUS is observed as "hiatus ballooning". Both levator avulsion and ballooning are associated with pelvic organ prolapse (POP) [1, 3, 5].

\section{Introital ulfrosound}

The technique involves the use of front-firing endovaginal probes placed on the vaginal introitus. It provides higher resolution of images but reduced penetration into the tissues. The effect of the Valsalva maneuver on proximal urethra mobility may be evaluated analogously to transperineal ultrasound (TPUS) using the inferior margin of the symphysis pubis as a reference $[3,4]$.

\section{Transvaginal ultrasound (TVUS)}

A variety of transducers have been successfully used transvaginally by different working groups for detailed or integrated imaging of the lower urogenital tract and pelvic floor. The biplane electronic (linear and transverse perpendicular arrays) probe provides detailed images of the anterior and posterior compartments (Figs. 2 and 3). Computer-controlled acquisition of parallel longitudinal 2D images enables high-resolution 3D reconstruction $[1,6]$. The $360^{\circ}$ rotational mechanical probe due to the internal automated motorized system enables acquisition of 300 aligned transaxial images over a distance of $60 \mathrm{~mm}$ without any movement of the probe within the tissue. The set of $2 \mathrm{D}$ images is reconstructed into a high-resolution 3D image for real-time manipulation and volume rendering $[1,6]$.

Conventional front-firing transvaginal probes may be useful for PVR measurement.

\section{Transabdominal ultrasound}

The main application of transabdominal ultrasound (TAUS) in urogynecology is measurement of PVR. In postoperative cases complicated by urine retention TAUS may be helpful in detection of underlying problems (see below).

\section{Endoanal ultrasound}

Endoanal ultrasound plays an important role in the work-up of defecatory disorders, anal incontinence or anal tumors. Its sensitivity and specificity for detecting anal sphincter defects ranges from 83 to 100\% [7]. It is the gold standard in proctology and is beyond the scope of this review. 
Role of ultrasound imaging in the clinical work-up of patients with urinary incontinence and/or pelvic organ prolapse

According to the recent International Federation of Gynecology and Obstetrics (FIGO) Working Group guidelines, the only useful application of ultrasound examination in the evaluation of patients with urinary incontinence is measurement of the post-void residual volume (PVR) [8]. This is in concert with recommendations provided by the $5^{\text {th }}$ International Consultation on Incontinence [9], which conclude that:

- ultrasound is not recommended in the primary evaluation of patients with urinary incontinence and/or pelvic organ prolapse [Level of evidence 3, Grade of recommendation $\mathrm{C}$,

- ultrasound is an optional test in the evaluation of patients with complex or recurrent urinary incontinence (UI) and/or pelvic organ prolapse (POP) [Level of evidence 3 , Grade of recommendation $\mathrm{C}]$.

Historically, many ultrasound findings have been taken into account as diagnostic of stress urinary incontinence (SUI) (Table I) [10-16].

Since there are no unequivocal data supporting their utility, it is unlikely that pretreatment ultrasound assessment will provide additional benefit. Bladder neck funneling (opening of the bladder neck on Valsalva or coughing) is a typical finding in women with SUI, but can be seen in asymptomatic women as well [17, 18]. It is also observed in urge $\mathrm{UI}$, and thus cannot be regarded as diagnostic for any of these conditions [19]. In conclusion, there is insufficient evidence for clinical benefit of standard evaluation of bladder neck funneling in patients with UI.

Descent of pelvic organs in cases of mild or moderate prolapse can be easily visualized by ultrasound during the Valsalva maneuver or coughing. Ultrasound imaging enables one to discriminate between cystourethrocele and isolated cystocele in the anterior compartment, and between rectocele and enterocele in the posterior compartment [1]. Transperitoneal ultrasound can be used to quantify the degree of prolapse. A fairly good correlation between ultrasound and clinical pro- lapse assessment has been demonstrated, i.e. $r=0.77$ for uterine prolapse, $r=0.72$ for anterior vaginal wall and $r=0.53$ for posterior vaginal wall descent [20]. It has not been documented, however, that ultrasound findings lead to better planning and outcomes of prolapse surgery.

Although contemporary guidelines recognize only limited utility of ultrasound in the management of $\mathrm{UI}$ and/or POP, in many instances ultrasound imaging may be very useful in decision making. This is mainly due to the fact that usually ultrasound examination is the most readily available non-invasive test for, at least, initial assessment. Potential "off-label" applications of ultrasound in patients with uncomplicated UI include detection of decreased urethral mobility before planning a surgical procedure for SUI and measurement of bladder wall thickness as a marker of detrusor instability. Moreover, on rare occasions, ultrasound may be helpful in recognition of pathologies mimicking vaginal prolapse such as vaginal cyst, urethral diverticula or rectal intussusception.

\section{Post-void residual volume measurement}

There is no agreement on what volume of urine left in the bladder after micturition may be considered normal. Studies showed that in the general population 15\% of women have post-void residual volume (PVR) greater than $50 \mathrm{ml}, 5 \%$ greater than $100 \mathrm{ml}, 6 \%$ greater than $149 \mathrm{ml}$ and $4 \%$ greater than $200 \mathrm{ml}[21,22]$. The recent FIGO Group guidelines, in concert with other recommendations, advise that volumes greater than $150 \mathrm{ml}$ should be regarded as abnormal [8]. Higher incidence of elevated PVR is observed among patients with stress urinary incontinence, previous incontinence surgery, overactive bladder, multiple sclerosis and pelvic organ prolapse stage 2 or greater [23]. According to Tseng et al., almost $16 \%$ of women with SUI have PVR $>100 \mathrm{ml}$ [24]. Therefore, measurement of PVR is recommended as a standard work-up in patients with UI or POP before and after the treatment. Due to high prevalence of urine retention and frequent need for clean intermittent catheterization, evaluation of PVR is of pivotal

Tab. I. Use of ultrasound imaging for diagnosis of stress urinary incontinence - selected studies

\begin{tabular}{llcc}
\hline Parameter & Approach & Sensitivity/specificity & Study \\
\hline Urine leakage & Transperineal & $75 \% / 77 \%$ & {$[10]$} \\
\hline Urine leakage & Transperineal & $94 \% / 98 \%$ & {$[11]$} \\
\hline Bladder neck funneling & Transperineal & $83 \% / 76 \%$ & {$[12]$} \\
\hline Bladder neck funneling & Introital & $94 \% / 98 \%$ & {$[13]$} \\
\hline Bladder neck hypermobility & Transperineal & $73 \% / 75 \%$ & {$[14]$} \\
\hline Vesico-urethral angle & Transrectal & $86 \% / 79 \%$ & {$[15]$} \\
\hline Vesico-urethral angle & Transperineal & $96 \% / 82 \%$ & {$[16]$} \\
\hline
\end{tabular}


importance in patients receiving intravesical injections of botulinum toxin A for urge UI [9].

Nowadays, ultrasound is the preferred method for PVR assessment in clinical practice, mainly due to its noninvasiveness $[8,9]$. Ultrasound estimations may be performed using either three diameters (length, height, width) or the surface area in the transverse image and the length obtained in the longitudinal image. Although more than 20 different formulae for PVR calculation have been proposed over the years, the inaccuracy of ultrasound measurements may be as high as $20-25 \%$. However, this level of accuracy is sufficient for clinical purposes. Measurement by catheterization is an invasive method, poorly tolerated by patients and often imprecise due to inadequate technique, bladder abnormalities (diverticula) or intensive diuresis [9].

\section{Bladder wall thickness as a marker of detrusor overoctivity}

Numerous studies using abdominal, transperineal or endovaginal ultrasound have shown increased bladder wall thickness (BWT) or detrusor wall thickness (DWT) in patients with detrusor overactivity (DO). This phenomenon is believed to reflect bladder wall hypertrophy secondary to frequent detrusor contractions during the storage phase. However, there is conflicting evidence on the value and accuracy of ultrasound BWT or DWT assessment in diagnosis of overactive bladder in female patients [9]. A systematic review performed by Latthe et al. [25], after assessment of the methodological quality of 190 studies, included only 5 for further analysis. Using a 5-mm cut-off for BWT for identifying DO, the sensitivity and specificity of this marker were $85 \%$ and $89 \%$ in one study [26] but $40 \%$ and $79 \%$ in another [27]. The authors concluded that there are insufficient data to reliably estimate accuracy of BWT in DO. A recent multicenter study including 687 women with overactive bladder compared the accuracy of transvaginal BWT assessment and urodynamic study. Due to very low sensitivity and specificity, BWT measurement showed no diagnostic or prognostic value [28]. Ultrasonographic measurement of BWT cannot be at the moment recommended as an accurate method of diagnosing DO.

\section{Urethral mobility (bladder neck mobility)}

Assessment of urethral mobility with the Q-tip test is advised as a standard diagnostic step in women with SUI. It is performed with a lubricated cottontipped swab inserted into the urethra. Measurements are taken at rest and on maximal straining. The angle $\geq 30^{\circ}$ defines urethral hypermobility [8].

On transperineal or introital ultrasound the position of the bladder neck at rest and on maximal Val- salva may be determined relative to the central line of the symphysis pubis (SP) or its inferoposterior margin. Since the entire SP is rarely visualized, drawing of the central line (axis) may be difficult [4]. Hennemann et al. [29] managed to draw the central line in only $12 \%$ of transperineal images. Therefore, using the inferoposterior margin of the SP as a reference is recommended, but care must be taken not to change the ultrasound position during the maneuver [4]. On Valsalva the bladder neck and proximal urethra rotate in the posteroinferior direction. The distal urethra remains stable due to the fact that together with the anterior vaginal wall it is tethered to the symphysis pubis and pelvic sidewalls. The hypermobility of the urethra is not well defined, and different cutoffs of 20,25 or $30 \mathrm{~mm}$ have been proposed [2, 3]. In one study amongst nulliparous continent women of approximately 20 years of age, the bladder neck descent varied between $1 \mathrm{~mm}$ and $40 \mathrm{~mm}$ [30]. Interestingly, a study on a twin model suggested that bladder neck mobility may be to some extent determined genetically [31].

Urethral hypermobility is considered to be related to stress urinary incontinence. However, decreased mobility (hypomobility) is a trait of greater importance in clinical practice, since it considerably increases the risk of sling failure. This is mainly due to the fact that urethral mobility is a prerequisite for suburethral sling action (see below). Hypomobility (Q-tip at maximal straining angle $\left\langle 30^{\circ}\right.$ ) is associated with a nearly twofold increase in sling failure [32]. In patients subjected to a repeat sling for recurrent or persistent SUI, limited mobility of the urethra detected by the Q-tip test or by ultrasound increases the risk of an unfavorable outcome more than 4 times [33].

In a study of Viereck et al. [34], patients treated with tension-free vaginal tape (TVT) with postoperative bladder neck mobility $\leq 10 \mathrm{~mm}$ had a 2.6-fold higher risk of failure, whereas postoperative mobility greater than $15 \mathrm{~mm}$ significantly reduced the risk $(R R=0.4)$. On balance, recognition of urethral hypomobility (or lack of hypermobility) puts patient at higher risk of sling failure and prompts consideration of other treatment options.

\section{Urethral diverticula}

Urethral diverticula (UD) affect 6-20 in 1,000,000 of the general population but may be observed in up to $1.4 \%$ of those with urinary incontinence [35-37]. Most probably UD develop from the periurethral glands obstructed and dilated as a consequence of chronic inflammation [38, 39]. A causative relationship with urethral surgery, dilatation or traumatic delivery has also been proposed [40]. The majority of diverticula are in the form of a simple pouch, but some can have complex morphology such as saddlebag or circumferential (Fig. 4). The classic presentation of UD includes the "three D's": 

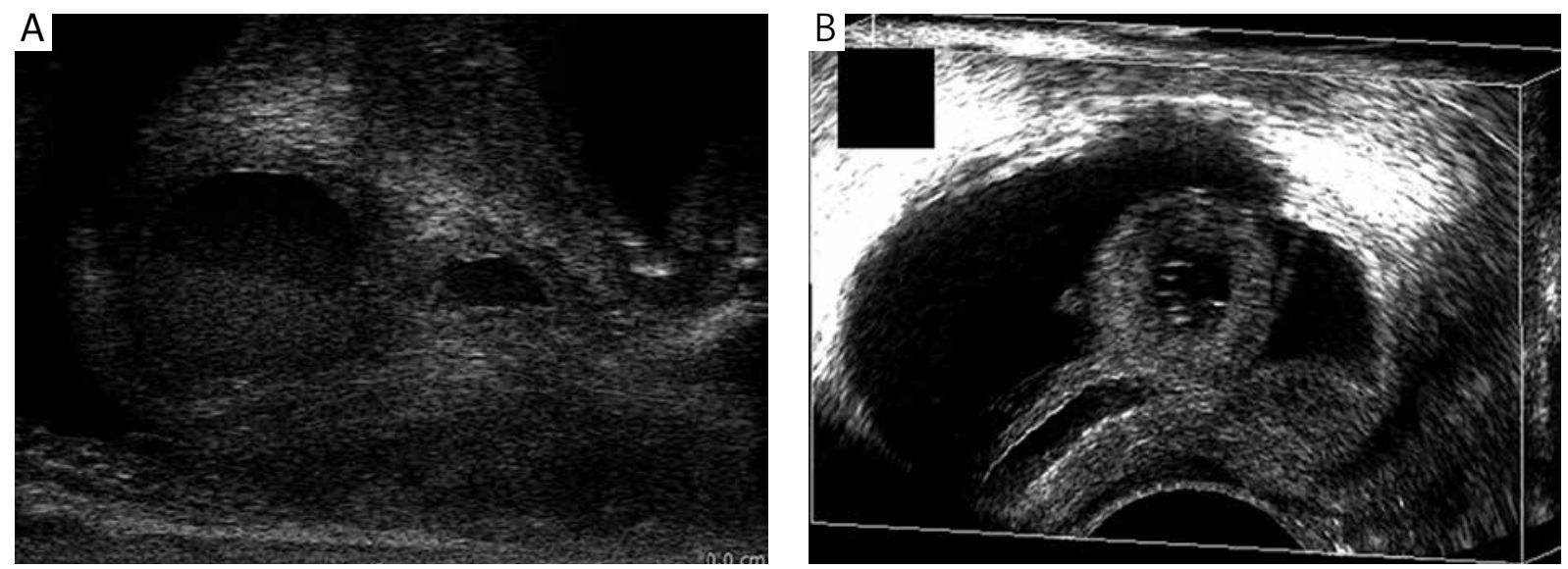

Fig. 4. Urethral diverticula of complex morphology: A) saddlebag (Courtesy of Prof. Andrzej P. Wieczorek, Medical University of Lublin), B) circumferential
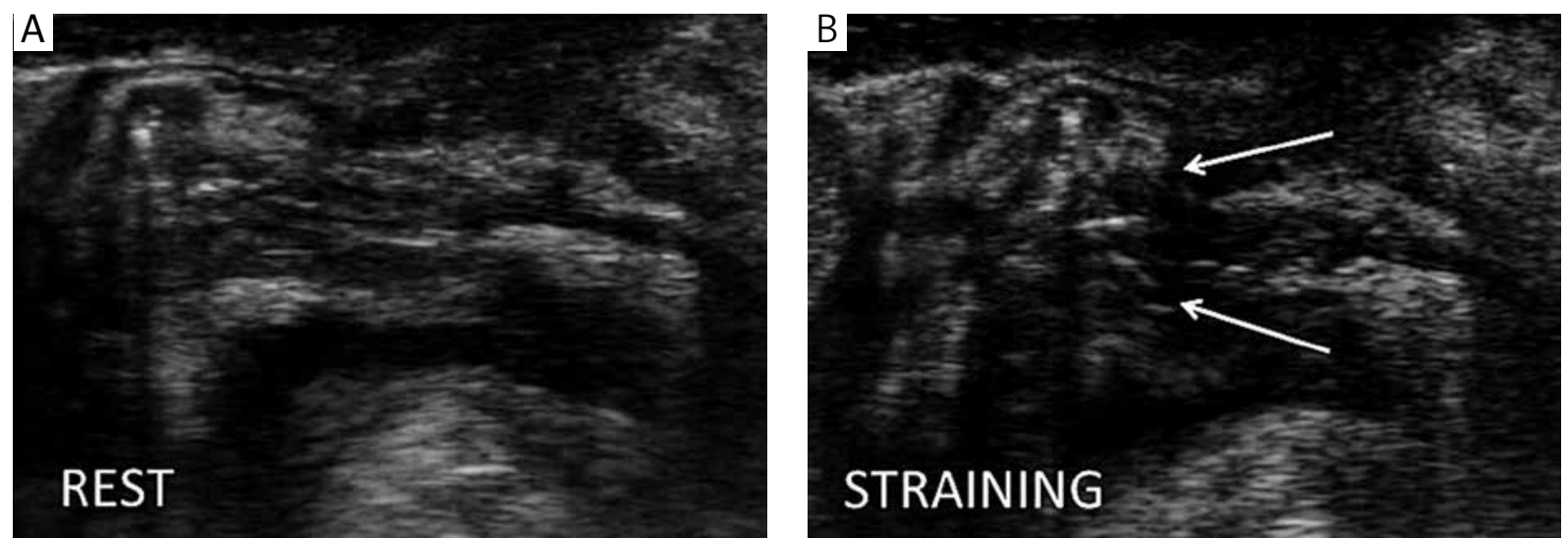

Fig. 5. Rectal intussusception. Invagination of rectal wall marked by arrows (Courtesy of Prof. Andrzej P. Wieczorek, Medical University of Lublin)

dysuria, dyspareunia and (post-void) dribbling. However, many nonspecific complains such as frequency, urgency, urinary incontinence, pain or discharge may be reported. On physical examination a periurethral mass, sometimes mimicking cystocele, can be palpated [38, 39]. Currently, MRI is regarded as the gold standard technique for imaging of UD. Sensitivity of transperineal or transvaginal ultrasound reached in some studies $95-100 \%$ [41, 42]; thus, ultrasound imaging may be recommended, at least, for initial assessment.

\section{Rectal infussusception}

Intussusception, first described in the $17^{\text {th }}$ century, is defined as the invagination of the proximal portion of the intestine into its distal portion in a telescope-like fashion [43]. In the case of rectal intussusception (RI) the full thickness of the rectal wall invaginates into the anal canal [44] (Fig. 5). This may produce a bulge of the posterior vaginal wall, easily mistaken for rectocele or enterocele. Ultrasound studies showed the RI prevalence of 3.9\% among urogynecologic patients and $4.3 \%$ among patients with obstructed defecation [45, 46].
It is more common in patients with a clinical diagnosis of rectocele or enterocele [45]. Defecation proctography is a standard method for detection of RI. However, this condition may be detected by two-dimensional or three-dimensional transperineal ultrasound with satisfactory levels of sensitivity and specificity [47]. Since transperineal ultrasonography is better tolerated than defecation proctography, this modality may well replace defecography as the initial examination of choice [48].

\section{Ultrasound in management of treatment failure and complications}

\section{Tape position and outcome of suburethral sling}

Synthetic implants are easily seen on TPUS, IUS or TVUS. In the case of suburethral slings ultrasound imaging enables precise localization of the tape position in relation to the urethra and other structures (Figs. 2, 6 and 7). There is a growing body of evidence that the position of the tape relative to the urethra is one of the most important factors determining sling outcome. 


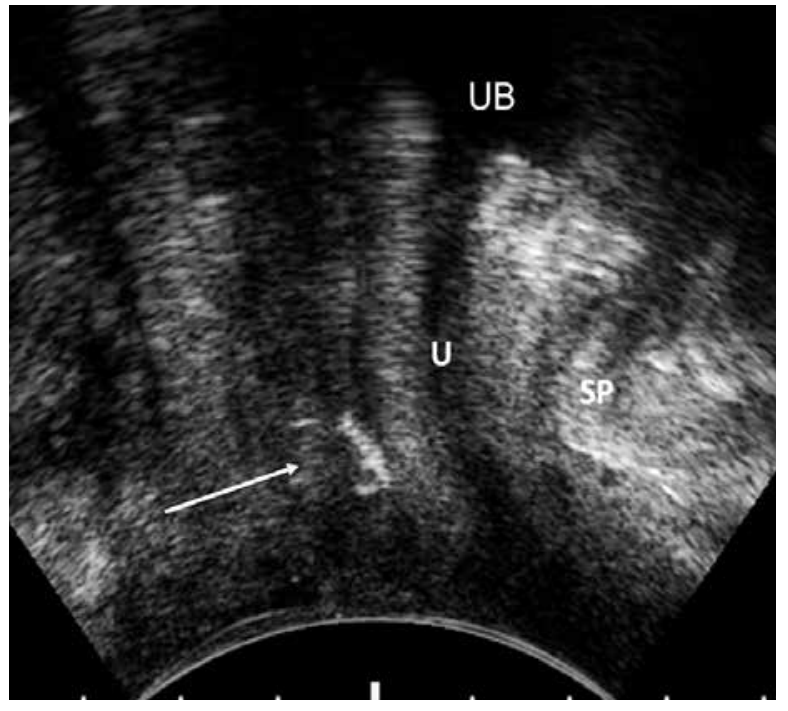

Fig. 6. Transperineal ultrasound. An "optimal" position of the tape under the urethra

Several studies have shown that optimally the tape should be placed between 50 and $75 \%$ of the urethral length, measured from the bladder neck to the external urethral meatus [49-52] (Figs. 2 and 6). This section corresponds to the high pressure zone of the urethra, which extends between the point of the maximum urethral closure pressure and the urethral knee [53].

The worst results are obtained when a tape is placed under the proximal urethra, with the failure rate exceeding $50 \%[52,54]$ (Fig. 7). In one study $74 \%$ of women with refractory or recurrent SUI treated with slings had the tapes positioned under the proximal half of the urethra [55].

Based on the integral theory of urinary incontinence, a key role of the tape inserted under the urethra is to reinforce weakened pubourethral ligaments. The tape positioned under the urethra creates a fulcrum on which

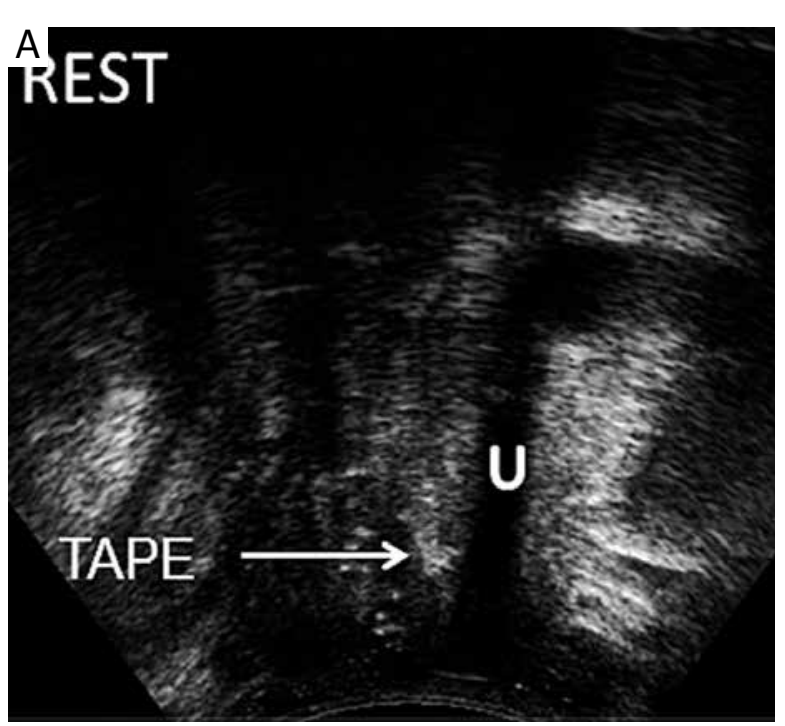

the urethra angulates (kinks) on straining (Fig. 7) [56]. Urethral 'kinking' is observed in approximately $90 \%$ of cured patient after retropubic slings, but only in $24-50 \%$ of cured patients after transobturator tapes [57-60]. Other modes of action have been proposed: compression of the urethra and surrounding tissue against the symphysis pubis or protrusion of the tape into the posterior wall of the urethra, with transient narrowing of its lumen ('urethral encroachment') [60]. It is not surprising that in case of location of a tape close to the bladder neck or immobile urethra, functioning of these mechanisms may be invalid.

Regarding the tension of the tape, an optimal distance between 3 and $5 \mathrm{~mm}$ from the implant to the urethral lumen, as measured on IUS, has been proposed. A distance shorter than $3 \mathrm{~mm}$ is associated with a greater risk of complications [49]. It is obvious that too much tension applied to the tape may cause voiding difficulties and development of de novo urgency. There are also reports linking the location of a tape close to the bladder neck to the development of de novo urgency (Fig. 8). However, in most patients this relationship is absent $[52,55,61]$.

Nevertheless, one should be aware of certain limitations. Clear relationships between ultrasound findings and patients' complaints have not been established, and data available in the literature are rarely directly applicable to individual cases. For instance, Lo and coworkers observed urethral kinking in 5 out of 10 patients with tapes positioned under the proximal urethra [60]. Moreover, in all studies a subset of patients benefited from slings implanted at the proximity of the bladder neck. In these cases continence may be restored by suspending the bladder neck and proximal urethra.

Attempts have been undertaken to improve the efficacy of sling procedures by preoperative measurement

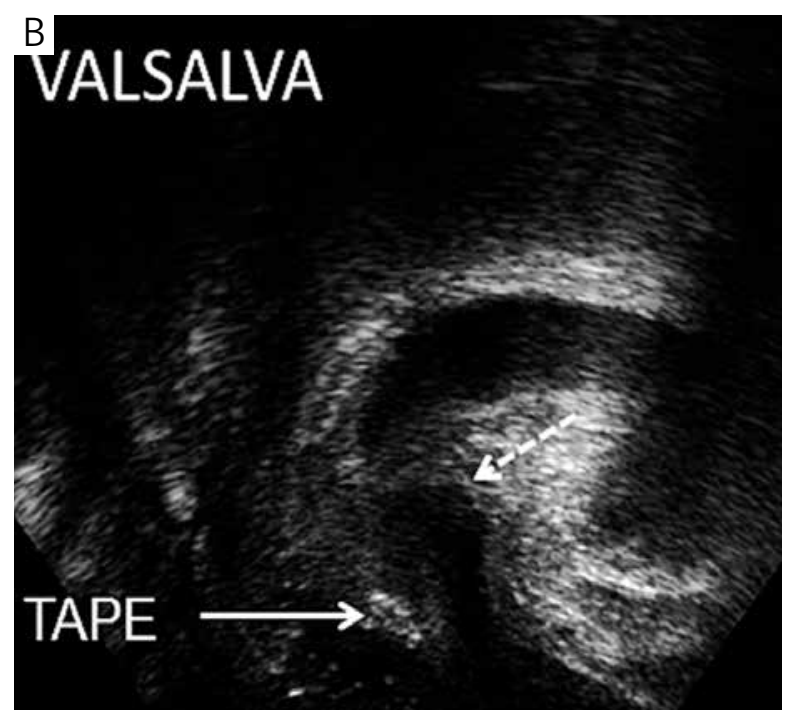

Fig. 7. Urethral angulation (kinking) of urethra on the tape. Urethral 'knee' marked by dotted arrow 

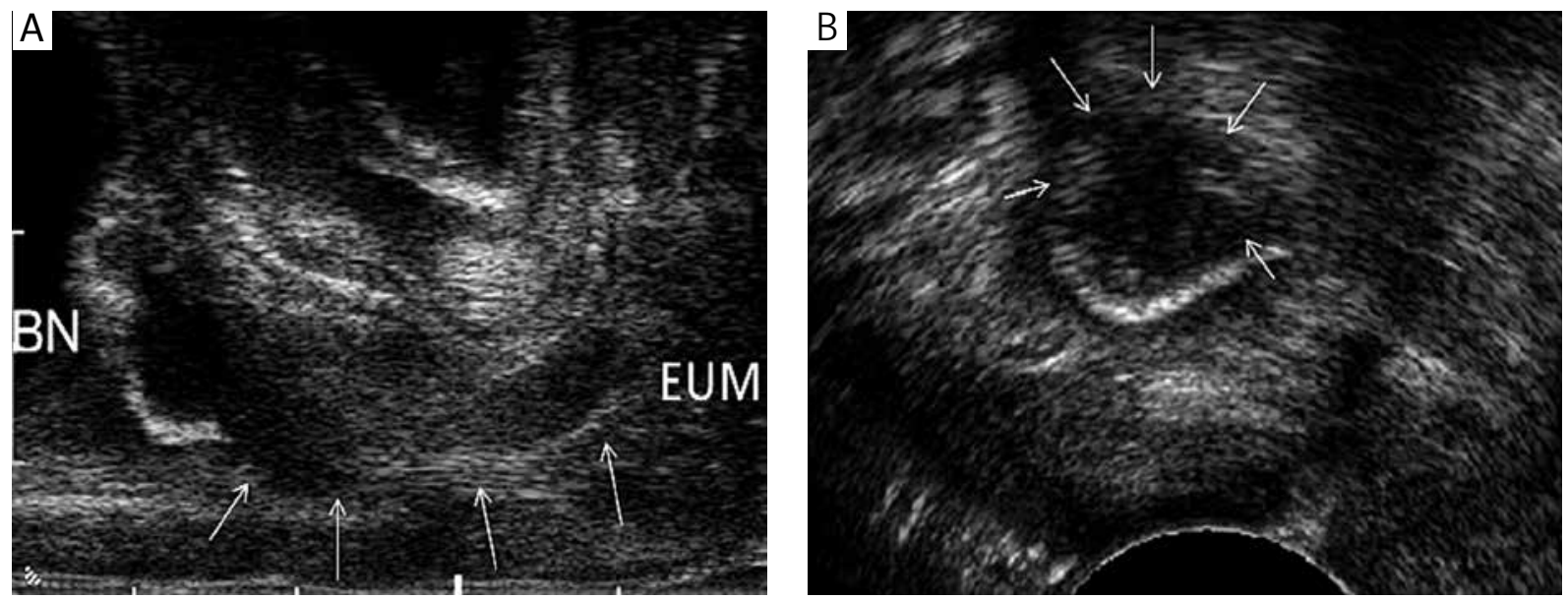

Fig. 8. Tape positioned "tightly" close to the bladder neck in a patient with sling failure followed by development of de novo urgency

of the urethral length and revising the site for the beginning of the suburethral incision of the vaginal wall. The one-third rule for retropubic and two-third rule for transobturator procedures have been proposed [62, 63]. The authors reported improved outcomes; however, due to some limitations of the studies, such as the relatively small number of patients and the short follow-up period (6 months), they do not justify application of this method in everyday practice. Moreover, as in the case of many reports concerning use of ultrasound imaging in urogynecology, the results have not been corroborated by other investigators.

In some cases incision or excision of a tape may be necessary due to patients' complaints or complications. The most common indications for sling incision are overactive bladder, voiding dysfunction and recurrent urinary tract infections [64]. To avoid long-term complications, Rautenberg et al. [65] performed early TVT mobilization in patients with postoperative voiding dysfunctions when the distance between the tape and the

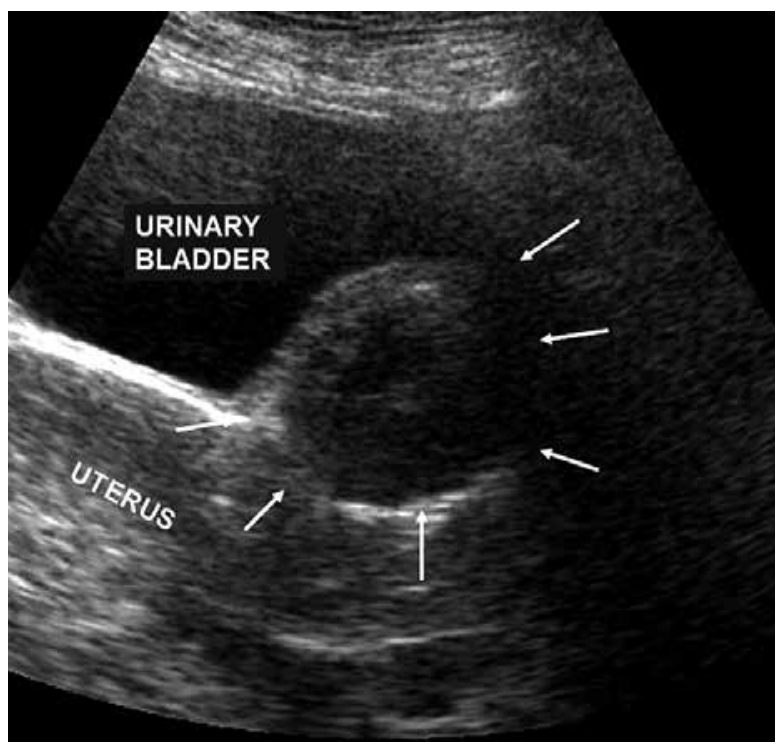

Fig. 9. Transabdominal ultrasound. Retroperitoneal hematoma with urine retention
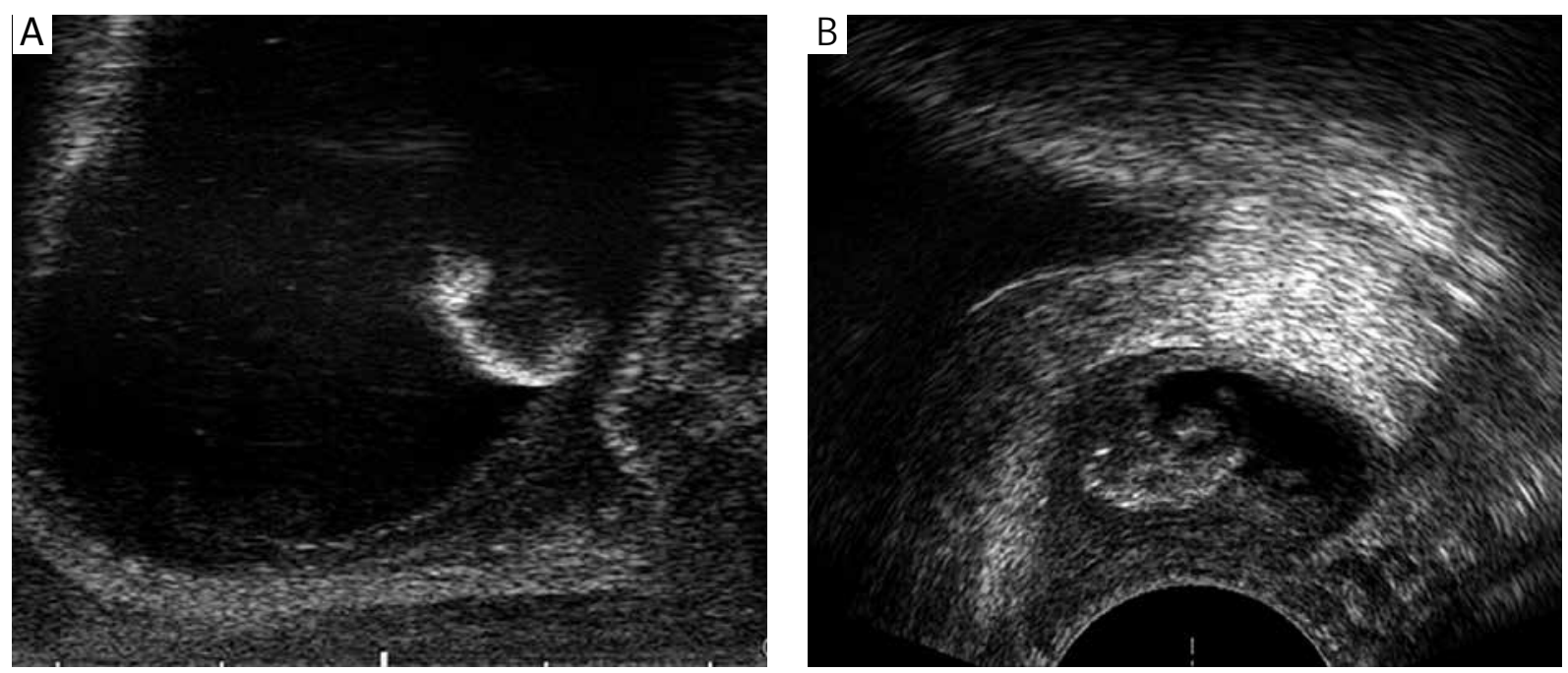

Fig. 10. Urinary tract injury during anterior vaginal mesh implantation. Penetration of the mesh arm into the bladder (A) and urether (B) 

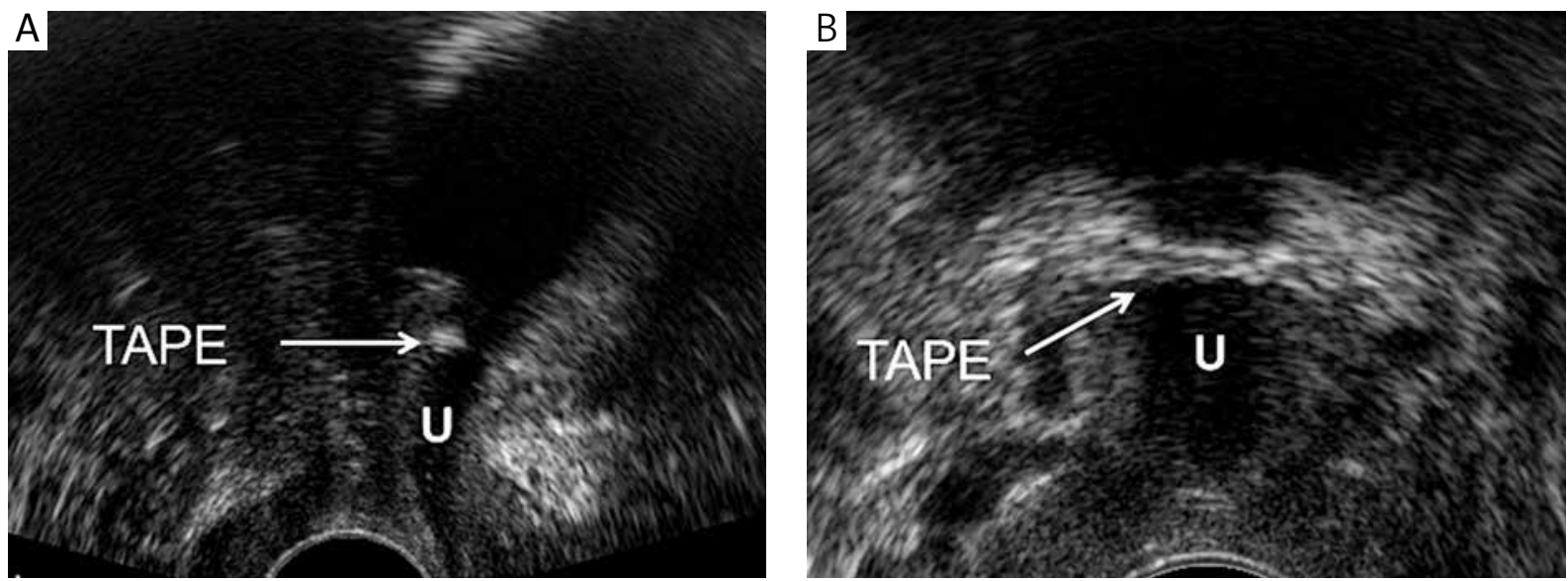

Fig. 11. The tape positioned tightly under the proximal urethra. Ultrasound examination suggest penetration of the tape into the urethra. This finding was not confirmed by cystoscopy

longitudinal smooth muscle layer of the urethra was $<3 \mathrm{~mm}$ and the PVR was > $100 \mathrm{ml}$. Normal voiding was restored in $96.7 \%$ of the patients and $95.1 \%$ of women were still continent at 6-month follow-up visits.

\section{Ultrasound for evaluation of patients treated with vaginal mesh}

Ultrasound is the best imaging modality for visualization of mesh implants. Nevertheless, there is a paucity of data regarding clinical application of ultrasound in patients after POP repair with meshes. A significant reduction in mesh dimensions (termed retraction, shrinkage or contraction), up to $60 \%$ of its original length, has been reported on ultrasound examination months or even days after surgery. The severity of retraction was associated with increased risk of prolapse recurrence, postoperative vaginal pain and de novo urgency [66-70]. Although these findings reasonably explain the pathogenesis of some unfavorable surgical outcomes, their value in everyday practice has not been demonstrated.

Up to $7.8 \%$ of mesh procedures are complicated by voiding dysfunction and urinary retention [71]. Occasionally, these complaints may be secondary to a retroperitoneal hematoma, which can be easily diagnosed by ultrasound (Fig. 9). Thus, ultrasound imaging may be recommended as an examination supplementary to physical assessment when formation of a hematoma is suspected, such as in cases of postoperative voiding dysfunction, defecatory dysfunction, excessive pain, vaginal bleeding or decreasing hemoglobin level [72].

Injury to the urethra, bladder or ureter usually is recognized and managed during surgery. On rare occasions patients with unrecognized injuries may present with fistulas, voiding disturbances or pelvic pain (Fig. 10). There are no systematic studies evaluating the value of ultrasound in detection of implants penetrating into the uri- nary tract. Ultrasound may be a reasonable first-choice tool, but US findings need to be confirmed by cystoscopy (Fig. 11).

\section{Disclosure}

Authors report no conflict of interest.

\section{References}

1. Santoro GA, Wieczorek AP, Dietz HP, et al. State of the art: an integrated approach to pelvic floor ultrasonography. Ultrasound Obstet Gynecol 2011; 37: 381-396.

2. Dietz HP. Ultrasound imaging of the pelvic floor. Part I: Two dimensional aspects. Ultrasound Obstet Gynecol 2004; 23: 80-92.

3. Dietz HP. Pelvic floor ultrasound: a review. Am J Obstet Gynecol 2010; 202: 321-334.

4. Tunn R, Schaer G, Peschers U, et al. Updated recommendations on ultrasonography in urogynecology. Int Urogynecol J Pelvic Floor Dysfunct 2005; 16: 236-241.

5. Dietz HP. Ultrasound imaging of the pelvic floor. Part II: three-dimensional or volume imaging. Ultrasound Obstet Gynecol 2004; 23: 615-625.

6. Santoro GA, Wieczorek AP, Stankiewicz A, et al. High-resolution threedimensional endovaginal ultrasonography in the assessment of pelvic floor anatomy: a preliminary study. Int Urogynecol J Pelvic Floor Dysfunct 2009; 20: 1213-1222.

7. Sultan AH, Kamm MA, Talbot IC, et al. Anal endosonography for identifying external sphincter defects confirmed histologically. Br I Surg 1994; 81: 463-465.

8. Medina CA, Costantini E, Petri E, et al. Evaluation and surgery for stress urinary incontinence: A FIGO working group report. Neurourol Urodyn 2016 [Epub ahead of print].

9. Tubaro A, Vodušek BD, Amarenco G, et al. Imaging, neurophysiological testing and other tests. In: Abrams P, Cardozo L, Khoury S, Wein A (eds.). Continence. $5^{\text {th }}$ International Consultation on Incontinence, Paris, February 2012, 507-621.

10. Dietz HP, McKnoulty L, Clarke B. Translabial color Doppler for imaging in urogynecology: a preliminary report. Ultrasound Obstet Gynecol 1999; 14: 144-147.

11. Dietz HP, Clarke B. Translabial color Doppler urodynamics. Int Urogynecol J Pelvic Floor Dysfunct 2001; 12: 304-307.

12. Dietz HP, Wilson PD. Anatomical assessment of the bladder outlet and proximal urethra using ultrasound and videocystourethrography. Int Urogynecol J Pelvic Floor Dysfunct 1998; 9: 365-369.

13. Quinn MJ, Farnsworh BA, Pollard WJ, et al. Vaginal ultrasound in the diagnosis of stress incontinence. Neurourol Urodyn 1989; 8: 302-303. 
14. Chen GD, Su TH, Lin LY. Applicability of perineal sonography in anatomical evaluation of bladder neck in women with and without genuine stress incontinence. J Clin Ultrasound 1997; 25: 189-194.

15. Bergman A, McKenzie CJ, Richmond J, et al. Transrectal ultrasound versus cystography in the evaluation of anatomical stress urinary incontinence. Br J Urol 1988; 62: 228-234.

16. Kölbl H, Bernaschek G, Wolf G. A comparative study of perineal ultrasound scanning and urethrocystography in patients with genuine stress incontinence. Arch Gynecol Obstet 1988; 244: 39-45.

17. Huang WC, Yang JM. Bladder neck funneling on ultrasound cystourethrography in primary stress urinary incontinence: a sign associated with urethral hypermobility and intrinsic sphincter deficiency. Urology 2003; 61: 936-941.

18. Schaer GN, Perucchini D, Munz E, et al. Sonographic evaluation of the bladder neck in continent and stress-incontinent women. Obstet Gynecol 1999; 93: 412-416.

19. Digesu GA, Khullar V, Cardozo L, Salvatore S. The open bladder neck: a significant finding? Int Urogynecol J Pelvic Floor Dysfunct 2004; 15 336-339.

20. Dietz HP, Haylen BT, Broome J. Ultrasound in the quantification of female pelvic organ prolapse. Ultrasound Obstet Gynecol 2001; 18: 511-514.

21. Sander P, Mouritsen L, Andersen JT, Fischer-Rasmussen W. Should measurement of maximum urinary flow rate and residual urine volume be a part of a "minimal care" assessment programme in female incontinence? Scand J Urol Nephrol 2002; 36: 124-127.

22. Gehrich A, Stany MP, Fischer JR, et al. Establishing a mean postvoid residual volume in asymptomatic perimenopausal and postmenopausal women. Obstet Gynecol 2007; 110: 827-832.

23. Fitzgerald MP, Jaffar J, Brubaker L. Risk factors for an elevated postvoid residual urine volume in women with symptoms of urinary urgency, frequency and urge incontience. Int Urogynecol J Pelvic Floor Dysfunct 2001; 12: 237-239.

24. Tseng LH, Liang CC, Chang YL, et al. Postvoid residual urine in women with stress incontinence. Neurourol Urodyn 2008; 27: 48-51.

25. Latthe PM, Champaneria R, Khan KS. Systematic review of the accuracy of ultrasound as the method of measuring bladder wall thickness in the diagnosis of detrusor overactivity. Int Urogynecol J 2010; 21: 1019-1024.

26. Khullar V, Cardozo LD, Salvatore S, Hill S. Ultrasound: a noninvasive screening test for detrusor instability. Br J Obstet Gynaecol 1996; 103 . 904-908.

27. Lekskulchai O, Dietz HP. Detrusor wall thickness as a test for detrusor overactivity in women. Ultrasound Obstet Gynecol 2008; 32: 535-539.

28. Rachaneni S, McCooty S, Middleton LJ, et al.; Bladder Ultrasound Study (BUS) Collaborative Group. Bladder ultrasonography for diagnosing detrusor overactivity: test accuracy study and economic evaluation Health Technol Assess 2016; 20: 1-150.

29. Hennemann J, Kennes LN, Maass N, Najjari L. Evaluation of established and new reference lines for the standardization of transperineal ultrasound. Ultrasound Obstet Gynecol 2014; 44: 610-616.

30. Dietz HP, Steensma AB, Vancaillie TG. Levator function in nulliparous women. Int Urogynecol J Pelvic Floor Dysfunct 2003; 14: 24-26.

31. Dietz HP, Hansell NK, Grace ME, et al. Bladder neck mobility is a heritable trait. BJOG 2005; 112: 334-339.

32. Richter HE, Litman HJ, Lukacs ES, et al. Demographic and clinical predictors of treatment failure one year after midurethral sling surgery. Urinary incontinence treatment network. Obstet Gynecol 2011; 117 913-921.

33. Lo TS, Pue LB, Tan YL, Wu PY. Risk factors for failure of repeat midurethral sling surgery for recurrent or persistent stress urinary incontinence. Int Urogynecol J 2016; 27: 923-931.

34. Viereck V, Nebel M, Bader W, et al. Role of bladder neck mobility and urethral closure pressure in predicting outcome of tension-free vaginal tape (TVT) procedure. Ultrasound Obstet Gynecol 2006; 28: 214-220.

35. El-Nashar SA, Bacon MM, Kim-Fine S, et al. Incidence of female urethral diverticulum: a population-based analysis and literature review. Int Uro gynecol J 2014; 25: 73-79.

36. Burrows LJ, Howden NL, Meyn L, Weber AM. Surgical procedures for ure thral diverticula in women in the United States, 1979-1997. Int Urogynecol J Pelvic Floor Dysfunct 2005; 16: 158-161.

37. Aldridge Jr CW, Beaton JH, Nanzig RP. A review of office urethroscopy and cystometry. Am J Obstet Gynecol 1978; 131: 432-437.
38. Crescenze IM, Goldman HB. Femal urethral diverticulum: current diagnosis and management. Curr Urol Rep 2015; 16: 71.

39. Rovner ES. Urethral diverticula: a review and an update. Neurourol Urodyn 2007; 26: 972-977.

40. Reeves FA, Inman RD, Chapple CR. Management of symptomatic urethral diverticula in women: a single-centre experience. Eur Urol 2014; 66: $164-172$

41. Gugliotta G, Calagna G, Adile G, et al. Use of trans-labial ultrasound in the diagnosis of female urethral diverticula: a diagnostic option to be strongly considered. J Obstet Gynaecol Res 2015; 41: 1108-1114.

42. Stav K, Dwyer PL, Rosamilia A, Chao F. Urinary symptoms before and after female urethral diverticulectomy - can we predict de novo stress urinary incontinence? J Urol 2008; 180: 2088-2090.

43. Barbete P. Ouevres Chirurgiques et Anatomiques. Francois Miege, Geneva $1674 ; 5221$.

44. Rodrigo N, Shek KL, Dietz HP. Rectal intussusception is associated with abnormal levator ani muscle structure and morphometry. Tech Coloproctol 2011; 15: 39-43.

45. Guzman Rojas R, Kamisan Atan I, Shek KL, Dietz HP. The prevalence of abnormal posterior compartment anatomy and its association with obstructed defecation symptoms in urogynecological patients. Int Urogynecol J 2016; 27: 939-944.

46. Rodrigo N, Shek KL, Dietz HP. Rectal intussusception is associated with abnormal levator ani muscle structure and morphometry. Tech Coloproctol 2011; 15: 39

47. Beer-Gabel M, Carter D. Comparison of dynamic transperineal ultrasound and defecography for the evaluation of pelvic floor disorders. Int J Colorectal Dis 2015; 30: 835-841.

48. Dietz HP. Translabial ultrasound in the assessment of pelvic floor and anorectal function in women with defecatory disorders. Tech Coloproctol 2014; 18: 481-494.

49. Kociszewski J, Rautenberg O, Perucchini D, et al. Tape functionality: sonographic tape characteristics and outcome after TVT incontinence surgery. Neurourol Urodyn 2008; 27: 485-490.

50. Yang JM, Yang SH, Huang WC. Correlation of morphological alterations and functional impairment of the tension-free vaginal tape obturator procedure. J Urol 2009; 181: 211-218.

51. Yang JM, Yang SH, Huang WC, Tzeng CR. Correlation of tape location and tension with surgical outcome after transobturator suburethral tape procedures. Ultrasound Obstet Gynecol 2012; 39: 458-465.

52. Bogusiewicz M, Monist M, Gałczyński K, et al. Both the middle and distal sections of the urethra may be regarded as optimal targets for 'outside-in' transobturator tape placement. World J Urol 2014; 32: 1605-1611.

53. Westby M, Asmussen M, Ulmsten U. Location of maximum intraurethral pressure related to urogenital diaphragm in the female subject as studied by simultaneous urethrocystometry and voiding urethrocystography. Am J Obstet Gynecol 1982; 144: 408-412.

54. Jiang YH, Wang CC, Chuang FC, et al. Positioning of a suburethral sling at the bladder neck is associated with a higher recurrence rate of stress urinary incontinence. J Ultrasound Med 2013; 32: 239-245.

55. Bogusiewicz M, Monist M, Stankiewicz A, et al. Most of the patients with suburethral sling failure have tapes located outside the high-pressure zone of the urethra. Ginekol Pol 2013; 84: 334-388.

56. Kuronen M, Schaer GN, Long C, et al. Clinical and ultrasonographic comparison of tension-free vaginal tape and transobturator tape procedure for the treatment of stress urinary incontinence. J Minim Invasive Gynecol 2008; 15: 425-430.

57. Long C, Hsu C, Lo T, et al. Ultrasonographic assessment of tape location following tensionfree vaginal tape and transobturator tape procedure. Acta Obstet Gynecol Scand 2008; 87: 116-121.

58. Foulot H, Uzan I, Chopin N, et al. Monarc transobturator sling system for the treatment of female urinary stress incontinence: results of a postoperative transvaginal ultrasonography. Int Urogynecol J Pelvic Floor Dysfunct 2007; 18: 857-867.

59. Yang S, Huang W. Dynamic interaction involved in the tension-free vaginal tape obturator procedure. J Urol 2008; 180: 2081-2087.

60. Lo TS, Wang AC, Horng SG, et al. Ultrasonographic and urodynamic evaluation after tension free vagina tape procedure (TVT). Acta Obstet Gynecol Scand 2001; 80: 65-70.

61. Wang F, Song Y, Huang $\mathrm{H}$. Which placement of the tension-free vaginal tape is more important for urinary continence: midurethral position or 
bladder neck? Consideration from a case report. Int Urogynecol J Pelvic Floor Dysfunct 2009; 20: 1277-1279.

62. Kociszewski J, Rautenberg O, Kuszka A, et al. Can we place tension-free vaginal tape where it should be? The one-third rule. Ultrasound Obstet Gynecol 2012; 39: 210-214.

63. Viereck V, Kuszka A, Rautenberg O, et al. Do different vaginal tapes need different suburethral incisions? The one-half rule. Neurourol Urodyn 2015; 34: 741-746.

64. Viereck V, Rautenberg O, Kociszewski J, et al. Midurethral sling incision: indications and outcomes. Int Urogynecol J 2013; 24: 645-653.

65. Rautenberg O, Kociszewski J, Welter J, et al. Ultrasound and early tape mobilization - a practical solution for treating postoperative voiding dysfunction. Neurourol Urodyn 2014; 33: 1147-1151.

66. Rogowski A, Bienkowski P, Tosiak A, et al. Mesh retraction correlates with vaginal pain and overactive bladder symptoms after anterior vaginal mesh repair. Int Urogynecol J 2013; 24: 2087-2092.

67. Tunn R, Schaer G, Peschers U, et al. Ultrasound appearances after mesh implantation - evidence of mesh contraction or folding? Int Urogynecol J 2011; 22: 529-533.

68. Velemir L, Amblard J, Fatton B, et al. Transvaginal mesh repair of anterior and posterior vaginal wall prolapse: a clinical and ultrasonographic study. Ultrasound Obstet Gynecol 2010; 35: 474-480.

69. Tunn R, Picot A, Marschke J, Gauruder-Burmester A. Sonomorphological evaluation of polypropylene mesh implants after vaginal mesh repair in women with cystocele or rectocele. Ultrasound Obstet Gynecol 2007; 29: 449-452.

70. Feiner B, O'Rourke P, Maher C. A prospective comparison of two commercial mesh kits in the management of anterior vaginal prolapse. Int Urogynecol J 2012; 23: 279-283.

71. Kannan K, Rane A. Pelvic haematoma after Perigee ${ }^{\mathrm{TM}}$ procedure for cystocoele. J Obstet Gynaecol 2010; 30: 524-525.

72. Huang WC, Yang JM. Voiding dysfunction related to a vaginal hematoma after a Perigee ${ }^{T M}$ procedure. Ultrasound Obstet Gynecol 2013; 41: 230-231. 